\title{
Toxic effects of chlortetracycline on maize growth, reactive oxygen species generation and the antioxidant response
}

\author{
Bei Wen ${ }^{1, *}$, Yu Liu ${ }^{1}$, Peng Wang ${ }^{1}$, Tong Wu ${ }^{1}$, Shuzhen Zhang ${ }^{1}$, \\ Xiaoquan Shan ${ }^{1}$, Jingfen $\mathrm{Lu}^{2}$ \\ 1. State Key Laboratory of Environmental Chemistry and Ecotoxicology, Research Center for Eco-Environmental Sciences, \\ Chinese Academy of Sciences, Beijing 100085, China. E-mail: bwen@rcees.ac.cn \\ 2. State Key Laboratory of Natural and Biomimetic Drugs, Health Science Center of Peking University, Beijing 100191, China
}

Received 17 August 2011; revised 08 October 2011; accepted 10 February 2012

\begin{abstract}
The toxicity of chlortetracycline (CTC) on maize (Zea mays L.) growth and reactive oxygen species (ROS) generation was studied. The root and shoot lengths and fresh weights of maize seedlings were inhibited by CTC treatment $(p<0.05)$. Root length was more sensitive than other parameters with the $\mathrm{EC}_{10}$ value of $0.064 \mathrm{mg} / \mathrm{L}$. The spin trapping technique followed by electron paramagnetic resonance (EPR) analysis was used to quantify the ROS production. The ROS generated in maize roots after exposure to CTC was identified as hydroxyl radical $(\cdot \mathrm{OH})$. The EPR signal intensity correlated positively with the logarithm of CTC concentrations exposed $(p<0.05)$. The dynamic changes of malondialdehyde (MDA) contents and the antioxidative enzyme activities in maize roots were also determined. As compared to the control group, CTC was found to significantly increase MDA content. Treatment of maize roots with the $\cdot \mathrm{OH}$ scavenger sodium benzoate (SB) reduced the MDA content and enhanced the antioxidative enzyme activities. The results demonstrated the harmfulness of CTC at high dose to maize in the early developmental stage, and clarified that the inducement of $\cdot \mathrm{OH}$ is one of the mechanisms of CTC toxicity.
\end{abstract}

Key words: maize (Zea mays L.); chlortetracycline; electron paramagnetic resonance (EPR); spin trapping; hydroxyl radical (.OH); antioxidant enzyme

DOI: $10.1016 / S 1001-0742(11) 60901-7$

\section{Introduction}

Antimicrobials are widely used to treat diseases and protect both human and animal health. They are also incorporated into animal feed to improve growth rate and feed efficiency. Hence a large percentage of the antibiotics are excreted and released into the environment (Jøgensen and Halling-Sønsen, 2000). Although many antibiotics have been reported to have relatively short environmental half-lives, they are assumed to possess the qualities of highly persistent pollutants because they are continually introduced into the environment. As a result, much attention has been paid to the ecological risk of antibiotics in the environment (Sarmah et al., 2006).

As well as the occurrence and fate of antibiotics in the environment (Kim and Carlson, 2007; Mompelat et al., 2009), the impacts of antibiotics in the environment on human and animal health, such as the promotion of the spread of antibiotic resistance or the triggering of adverse immunological reactions, have gained major attention $(\mathrm{Hu}$ et al., 2008; Matyar et al., 2008); however, knowledge of antibiotic uptake and toxicity to non-target organisms, such

\footnotetext{
* Corresponding author. E-mail: bwen@rcees.ac.cn
}

as plants, is incomplete.

A few studies have reported the uptake and toxicity of antibiotics to plants. Results obtained by Boxall et al. (2006) showed that florfenicol, levamisole, and trimethoprim could be taken up by lettuces, whereas diazinon, enrofloxacin, florfenicol, and trimethoprim were detected in carrot roots. The uptake of antibiotics in corn, green onion and cabbage increased with increasing amounts of antibiotics present in applied manure (Kumar et al., 2005). Oxytetracycline was observed to inhibit the growth of alfalfa shoots and roots by up to $61 \%$ and $85 \%$, respectively (Kong et al., 2007). Uptake and phytotoxicity of enrofloxacin on crop plants were reported by Migliore et al. (2003) and a toxic effect was induced by enrofloxacin at the concentration of $5000 \mu \mathrm{g} / \mathrm{L}$.

Chlortetracycline is one of the most widely used antimicrobials and has been found in a variety of environmental samples (Sarmah et al., 2006). Although the toxic effects of CTC to plants have been reported (Farkas et al., 2007; Liu et al., 2009), to our knowledge there is currently no study of the toxic mechanisms of CTC to plants available in the literature. The objective of this study was to investigate the potential oxidative stress induced by reactive oxygen 
species (ROS) in vivo. The contents of malondialdehyde (MDA), and the activities of antioxidative enzymes, including peroxidases (POD), superoxide dismutase (SOD), and catalase (CAT) in maize seedlings were also determined.

\section{Materials and methods}

\subsection{Chemicals}

Chlortetracycline (purity $>99 \%$ ), $\alpha$-phenyl-N-tertbutylnitrone (PBN, purity $>98 \%$ ), dimethylsulfoxide (DMSO, purity > 99.9\%), methyl gallate (MG), methanol, acetonitrile, dichloromethane, isopropanol, and sodium benzoate (SB) were purchased form Sigma-Aldrich, USA. Other reagents obtained domestically were of analytical grade (Sinopharm Chemical Reagent Co., Ltd., China).

\subsection{Plant culture}

Maize (Zea mays L. TY2) seeds obtained from the Chinese Academy of Agricultural Sciences (Beijing, China) were surface-sterilized with $2.5 \%$ sodium hypochlorite for 15 min followed by thorough washing in distilled water, and placed in $9 \mathrm{~cm}$ Petri dishes containing $25 \mathrm{~mL}$ of distilled water at $37^{\circ} \mathrm{C}$ in darkness. After 5 days of incubation, uniformly germinated seeds were selected and transferred to vitreous pots containing $20 \mathrm{~mL}$ of test solutions of 0.05 $50 \mathrm{mg} / \mathrm{L}$ CTC. Each pot contained 20 germinated seeds, and was kept at $25^{\circ} \mathrm{C}$ for 5 more days. Controls were maintained with $20 \mathrm{~mL}$ deionized water. Each treatment was replicated three times. A standard solution was prepared by dissolving $100 \mathrm{mg}$ CTC in $100 \mathrm{~mL}$ methanol containing $0.02 \mathrm{~mol} / \mathrm{L}$ sodium hydroxide, and stored in the dark at $0-4^{\circ} \mathrm{C}$. Working solutions of CTC $(0,0.05$, $0.5,5$, and $50 \mathrm{mg} / \mathrm{L}$ ) were prepared daily by diluting stock solution with deionized water. The $\mathrm{pH}$ was adjusted to 5.8. The culture solutions were renewed every day. During the 5-day exposure, maize roots were sampled, and MDA content and antioxidative enzyme activities were analyzed every day. After 5 days, the length of shoots and roots was measured. The biomass of roots and shoots was weighed after separation. Electro paramagnetic resonance (EPR) determination on roots was performed immediately. The remnant materials were frozen in liquid nitrogen immediately and stored at $-80^{\circ} \mathrm{C}$ for subsequent analysis.

CTC concentrations of exposure solutions were assessed by high performance liquid chromatography (HPLC). Measured concentrations were within $5 \%$ of nominal concentrations. Thus, calculated exposure levels were based on nominal concentrations.

\subsection{ROS inhibitor treatments}

For inhibitor experiments, maize seedlings were treated with a mixture of $200 \mu \mathrm{mol} / \mathrm{L} \mathrm{SB}$ and $50.0 \mathrm{mg} / \mathrm{L} \mathrm{CTC}$ and cultured for 5 days. Sodium benzoate was dissolved in distilled water. The MDA contents and antioxidative enzyme activities in maize roots were determined every day.

\subsection{PBN adduct extraction and Fenton reaction}

The spin trapping-EPR method was used for detection of ROS, for which PBN was applied as a spin trap. PBN adduct in maize roots was determined according to the method described by Shi et al. (2005) with some modifications. The whole operation was conducted under nitrogen. After being rinsed with ice-cold $0.1 \mathrm{~mol} / \mathrm{L} \mathrm{CaCl}_{2}$ solution, the maize roots were cut into small pieces, weighed $(0.8 \mathrm{~g})$, placed in a mortar and homogenized quickly with $0.8 \mathrm{~mL}$ freshly prepared solution of $100 \mathrm{mmol} / \mathrm{L} \mathrm{PBN}$ (dissolved in DMSO). The homogenates were then centrifuged at $4500 \mathrm{r} / \mathrm{min}$ for $3 \mathrm{~min}$ at $4^{\circ} \mathrm{C}$. The supernatant was collected and incubated at $37^{\circ} \mathrm{C}$ for $15 \mathrm{~min}$. The supernatant $30 \mu \mathrm{L}$ was transferred to a capillary tube with a diameter of 1.0 mm for EPR analysis.

Fenton reactions were conducted under both aerobic and anaerobic conditions to identify the original free radicals of free radical adducts. One milliliter of air-saturated solution of $125 \mathrm{mmol} / \mathrm{L} \mathrm{PBN}$ and $5 \mathrm{~mol} / \mathrm{L} \mathrm{DMSO}$ in $50 \mathrm{mmol} / \mathrm{L}$ phosphate-buffered saline (PBS, $\mathrm{pH}$ 6.5) was mixed with $20 \mu \mathrm{L}$ of $100 \mathrm{mmol} / \mathrm{L} \mathrm{H}_{2} \mathrm{O}_{2}$ and $100 \mu \mathrm{L}$ of $1 \mathrm{mmol} / \mathrm{L}$ $\mathrm{FeSO}_{4}$, then incubated in air for $15 \mathrm{~min}$. For the anaerobic reaction, $\mathrm{PBN}$ and DMSO in phosphate buffer purged with nitrogen was mixed with $\mathrm{H}_{2} \mathrm{O}_{2}$ and $\mathrm{FeSO}_{4}$ and reacted under nitrogen atmosphere.

\subsection{EPR analysis}

The EPR spectra were recorded with a Bruker ESP 300 spectrometer (Bruker, Germany) at room temperature. The operational conditions were: microwave power $20 \mathrm{~mW}$, microwave frequency $9.7 \mathrm{GHz}$, center field, $3470 \mathrm{G}$; scan range, $100 \mathrm{G}$; modulation frequency, $100 \mathrm{kHz}$; modulation amplitude, $2.5 \mathrm{G}$; receiver gain, $2 \times 10^{4}$ scans. The intensities of free radicals were calculated according to the heights of the central peaks of EPR signals.

\subsection{Determination of CTC in maize roots}

Chlortetracycline was extracted from maize according to the method of Spisso et al. (2007) with some modifications. The germinated seed roots (3-4 g) were weighed and ground. Two sequential volumes $(5 \mathrm{~mL}$ for each) of 0.1 mol/L EDTA in McIlvaine buffer ( $\mathrm{pH} 4.0$ ) were used. After shaking for $5 \mathrm{~min}$ and sonication for $10 \mathrm{~min}$, the mixture was centrifuged at $4000 \times g$ for $10 \mathrm{~min}$, the supernatant was transferred to a clean tube and the extraction was repeated. The combined extracts were filtered through a $0.45 \mu \mathrm{m}$ filter and the filtrate was applied to a previously activated Oasis HLB cartridge (6 mL/300 mg, Waters, MA, USA). After washing three times with $1 \mathrm{~mL}$ methanol (15\% in water) and twice with $1 \mathrm{~mL}$ of acetonitrile (5\% in water), the cartridge was vacuum-dried, and the retained CTC was eluted with two $1 \mathrm{~mL}$ dichloromethane:isopropanol 80:20 $(V / V)$. The eluted solution was collected, and evaporated to dryness with $\mathrm{N}_{2}$ at $45-55^{\circ} \mathrm{C}$. The residue was reconstituted with $1 \mathrm{~mL}$ mixed solution of $85 \%$ solvent $\mathrm{A}(0.1 \mathrm{~mol} / \mathrm{L}$ malonate, $\left.50 \mathrm{mmol} / \mathrm{L} \mathrm{MgCl}_{2}, \mathrm{pH} 6.5\right)$ and $15 \%$ solvent $\mathrm{B}$ (methanol) before injection.

All measurements were performed according to the 
method of Schneider et al. (2007) using a HPLC instrument (Agilent 1200, Agilent Technologies, Wilmington, DE, USA) equipped with fluorescence detector. The chromatographic separation was carried out in an AtlantisdC18 ODS HPLC column (4.6 i.d. $\times 150 \mathrm{~mm}, 5 \mu \mathrm{m}$, Waters, MA, USA). Isocratic elution was performed at a flow rate of $0.6 \mathrm{~mL} / \mathrm{min}$ using the mobile phase $85 \%$ solvent $\mathrm{A}$ and $15 \%$ solvent $\mathrm{B}$. The excitation and emission wavelengths for detection were 379 and $528 \mathrm{~nm}$, respectively. Under these conditions CTC showed a single peak at the retention time of $9.1 \mathrm{~min}$. The quantification limit was $2.5 \mu \mathrm{g} / \mathrm{L}$.

\subsection{Determination of MDA and antioxidative enzymes}

MDA was measured by a colorimetric method (Heath and Packer, 1968). The absorbance of thiobarbituric acidreactive substances in the reactive mixture was measured at 532 and $600 \mathrm{~nm}$. The absorbance of the MDA was read at $532 \mathrm{~nm}$ and the nonspecific absorption at $600 \mathrm{~nm}$ was subtracted. The concentration of MDA was calculated using its extinction coefficient $(155 \mathrm{mmol} /(\mathrm{L} \cdot \mathrm{cm}))$.

Enzyme solutions were extracted from the fresh seedling roots under liquid nitrogen. Fresh seedling roots $(1.0 \mathrm{~g})$ were homogenized in $10 \mathrm{~mL}$ of extraction buffer $(0.05$ $\mathrm{mol} / \mathrm{L} \mathrm{NaH} \mathrm{PO}_{4}+\mathrm{Na}_{2} \mathrm{HPO}_{4}$ in $1 \%$ polyvinylpyrrolidone, pH 7.8). The details were described by Polle et al. (1997). After filtration through four layers of cheesecloth to remove debris, the homogenate was centrifuged at 10,000 $\times g$ for $10 \mathrm{~min}$. All steps were performed at $4{ }^{\circ} \mathrm{C}$. The supernatant was used for enzyme activity and soluble protein assays. Protein level were measured by the method of Bradford (1976) using bovine serum albumin as a standard. The SOD activities were assayed on the basis of its ability to inhibit the photochemical reduction of nitro blue tetrazolium (Beauchamp and Fridovich, 1971). The reaction mixture contained $50 \mathrm{mmol} / \mathrm{L}$ phosphate buffer ( $\mathrm{pH} 7.8$ ), $13 \mathrm{mmol} / \mathrm{L}$ methionine, $75 \mathrm{mmol} / \mathrm{L}$ nitro blue tetrazolium, $2 \mathrm{mmol} / \mathrm{L}$ riboflavin, $100 \mathrm{nmol} / \mathrm{L}$ EDTA, and $0-200 \mu \mathrm{L}$ of enzyme extract. The riboflavin was added last. The reaction mixture was read at $560 \mathrm{~nm}$. One unit of SOD activity (U) was defined as the amount of enzyme that caused $50 \%$ inhibition of the initial rate of the reaction in the absence of enzyme. Total SOD activity was expressed as $\mathrm{U} / \mathrm{mg}$ protein. Catalase (CAT) was measured by the method of Aebi (1984). The principle of the method was based on the hydrolysis of $\mathrm{H}_{2} \mathrm{O}_{2}$ and decreasing absorbance at $240 \mathrm{~nm}$. The amount of enzyme that catalyzes $1 \mu \mathrm{mol}$ of $\mathrm{H}_{2} \mathrm{O}_{2}$ decomposition per min was considered as one unit of enzyme activity (U) and CAT activity was expressed as U/mg protein. Peroxidase (POD) activity was determined with guaiacol by spectrophotometry (Lagrimini, 1991). In the presence of $\mathrm{H}_{2} \mathrm{O}_{2}$, POD catalyzes the transformation of guaiacol to tetraguaiacol. This reaction can be recorded at $470 \mathrm{~nm}$. The reaction mixture contained $100 \mathrm{mmol} / \mathrm{L}$ phosphate buffer ( $\mathrm{pH}$ 6.0), $33 \mathrm{mmol} / \mathrm{L}$ guaiacol and $0.3 \mathrm{mmol} / \mathrm{L} \mathrm{H}_{2} \mathrm{O}_{2}$. Activity was calculated using the extinction coefficient of $26.6 \mathrm{~L} /(\mathrm{mmol} \cdot \mathrm{cm})$ at $470 \mathrm{~nm}$ for tetraguaiacol. One unit of POD was defined as the amount of enzyme that causes the formation of $1 \mu \mathrm{mol}$ tetraguaiacol per min.

\subsection{Statistical analysis}

All data presented were expressed as mean \pm standard deviation (SD). Statistical analysis was performed using Origin 7.0 and SPSS 11.5. The data represent means calculated from five replicates. Comparisons between control and treatments were evaluated by one-way ANOVA using the least-significant difference. $\mathrm{EC}_{50}$ values (the concentration causing $50 \%$ effect) as well as $\mathrm{EC}_{10}$ values (the concentration causing $10 \%$ effect) of the tested antibiotics were calculated by plotting the logarithm of CTC concentrations versus plant growth endpoints (roots and shoots length and biomass).

\section{Results and discussions}

\subsection{Toxic effect of CTC on maize}

The effects of CTC on the length and biomass of maize shoots and roots are presented in Fig 1. CTC treatment at the level of $0.05 \mathrm{mg} / \mathrm{L}$ exhibited no toxic effects on maize growth. When the concentration of CTC was higher than $0.5 \mathrm{mg} / \mathrm{L}$, the maize root and shoot lengths and fresh weights decreased significantly $(p<0.05)$. A negative relationship was found between the logarithm of CTC concentrations in solutions and the root and shoot fresh
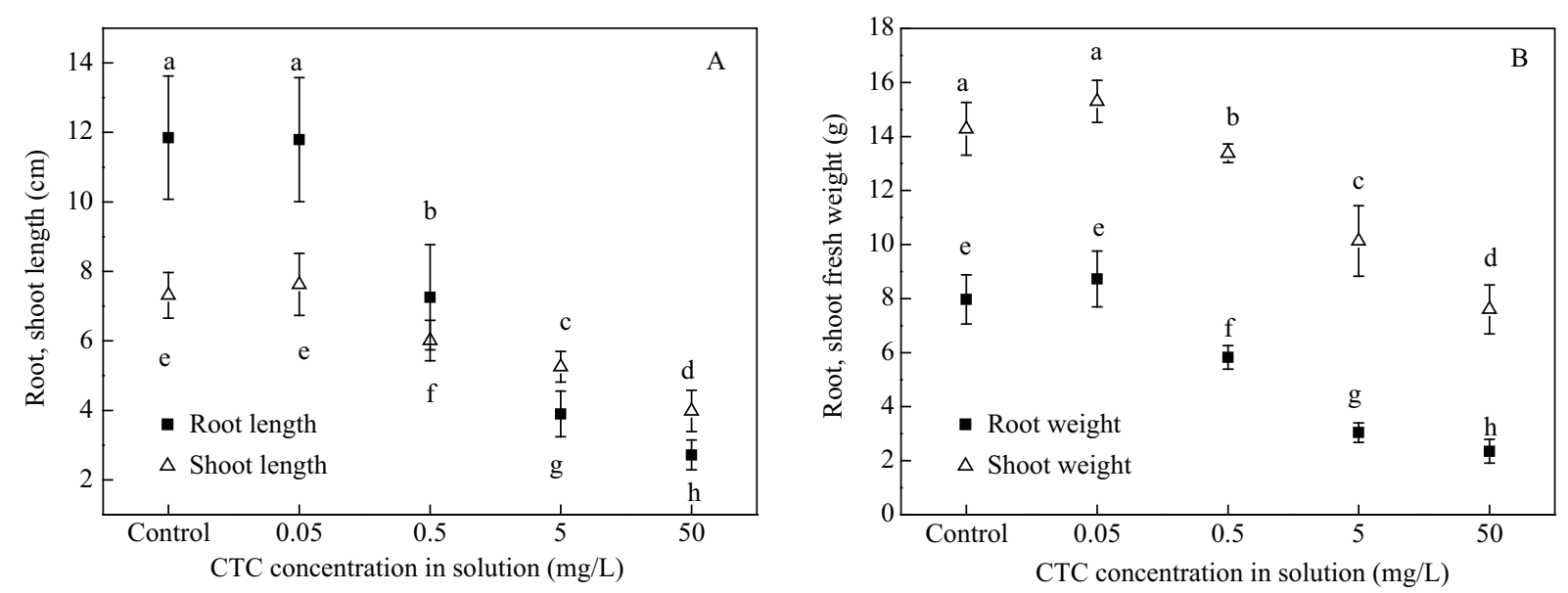

Fig. 1 Effect of CTC on root and shoot length (A) and biomass (B). Different letters indicate significant differences at $p<0.05$. 
Table 1 Inhibition dose of CTC on maize early developmental stages and their relationships $(n=6)$

\begin{tabular}{lllll}
\hline Endpoints & $\mathrm{EC}_{10}(\mathrm{mg} / \mathrm{L})$ & $\mathrm{EC}_{50}(\mathrm{mg} / \mathrm{L})$ & Equation & $R^{2}$ \\
\hline Root length & 0.064 & 2.287 & $Y_{\mathrm{rl}}=-3.06 x+7.02$ & $0.942^{*}$ \\
Shoot length & 0.298 & 92.18 & $Y_{\mathrm{sl}}=-1.17 x+5.95$ & $0.982^{* *}$ \\
Root biomass & 0.158 & 2.329 & $Y_{\mathrm{rb}}=-2.19 x+5.42$ & $0.944^{*}$ \\
Shoot biomass & 0.527 & 75.75 & $Y_{\mathrm{sb}}=-2.64 x+12.13$ & $0.991^{* *}$ \\
\hline
\end{tabular}

$*$ and $* *$ represent significance at $p<0.05$ and $p<0.01$, respectively.

$\mathrm{EC}_{50}$ and $\mathrm{EC}_{10}$ values are the concentration causing $50 \%$ effect and $10 \%$ effect, respectively.

$Y$ : inhibition rate of seedling, $Y_{\mathrm{rl}}$ : root length; $Y_{\mathrm{sl}}$ : shoot length; $Y_{\mathrm{rb}}$ : root biomass; $Y_{\mathrm{sb}}$ : shoot biomass; $x$ : log concentration of CTC.

weights and lengths $(p<0.05)$, with $R^{2}$ values higher than 0.94 (Table 1).

The increases in the concentration of CTC in the growth medium led to a more pronounced reduction in root length than the other parameters (Table 1), suggesting that root length was the best CTC toxicity indicator. Plant roots were the first point of contact for toxic CTC in the growth media. When uptake of nutrition was inhibited in roots, the growth of the whole plant was constrained, and the plant biomass decreased finally. Liu et al. (2009) also applied root lengths as endpoint to study the phytotoxicity of antibiotics to sweet oat, rice and cucumber using a seed germination test. They found that the phytotoxic effects varied between plant species. Sweet oat was the most sensitive species to CTC with the $\mathrm{EC}_{10}$ value of $0.2 \mathrm{mg} / \mathrm{L}$. In this study, the $\mathrm{EC}_{10}$ value of maize was $0.064 \mathrm{mg} / \mathrm{L}$, suggesting that CTC was more toxic to maize seedlings than to sweet oat.

\subsection{Free radical generation in maize roots}

The exposure of maize to CTC resulted in an increase in the six-line EPR signal of PBN radical adducts in the maize roots (Fig. 2 lines a-e). The hyperfine coupling constants of the PBN adducts were $\alpha^{\mathrm{N}}=14.9 \mathrm{G}, \alpha^{\mathrm{H}}=2.9 \mathrm{G}, \alpha^{\mathrm{N}}=$

$\nabla$ Signal of $\mathrm{PBN} / \cdot \mathrm{OCH}_{3} \quad \nabla$ Signal of $\mathrm{PBN} / \cdot \mathrm{CH}_{3}$

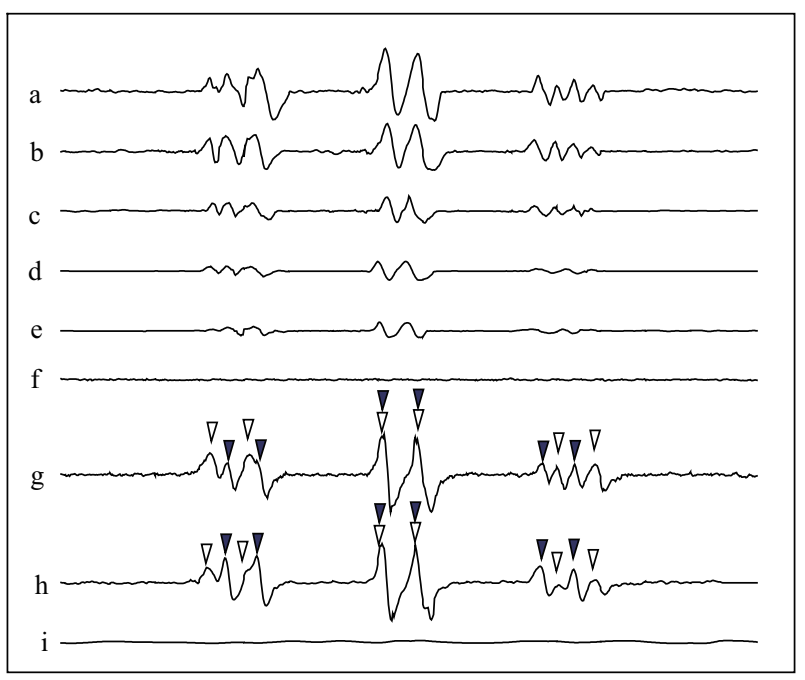

Fig. 2 EPR detection of the $\alpha$-phenyl-N-tert-butylnitrone adducts in maize root after CTC exposure. Spectra (a)-(f) represent the following treatments: (line a) $50.0 \mathrm{mg} / \mathrm{L} \mathrm{CTC;} \mathrm{(line} \mathrm{b)} 5 \mathrm{mg} / \mathrm{L} \mathrm{CTC;} \mathrm{(line} \mathrm{c)}$ $0.5 \mathrm{mg} / \mathrm{L} \mathrm{CTC}$; (line d) $0.05 \mathrm{mg} / \mathrm{L} \mathrm{CTC}$; (line e) control; (line f) PBN and DMSO without roots. The Fenton reaction was carried out under anaerobic (line g) and aerobic (line $\mathrm{h}$ ) conditions; control (line i): 0.2 $\mathrm{mL}$ of $100 \mathrm{mmol} / \mathrm{L}$ methyl gallate was added before the addition of PBN and DMSO.
16.2 G, $\alpha^{\mathrm{H}}=3.5 \mathrm{G}$ and $g=2.0062$, which correspond to those of PBN/methoxy radical $\left(\cdot \mathrm{OCH}_{3}\right)$ and $\mathrm{PBN} /$ methyl radical $\left(\cdot \mathrm{CH}_{3}\right.$ ), respectively (Shi et al., 2005). PBN itself was examined and no PBN adduct was observed (Fig. 2 line $\mathrm{f})$. It was reported that the reaction of DMSO with hydroxyl radical $(\cdot \mathrm{OH})$ produced $\cdot \mathrm{CH}_{3}$ (Takeshita et al., 2004), and then $\cdot \mathrm{CH}_{3}$ may be oxidized to $\cdot \mathrm{OCH}_{3}$ under aerobic conditions (Takeshita et al., 2004). In order to demonstrate the oxidation of $\cdot \mathrm{CH}_{3}$ to $\cdot \mathrm{OCH}_{3}$, the Fenton reaction was conducted under both anaerobic and aerobic conditions. The results of PBN adduct signals showed the coexistence of $\cdot \mathrm{CH}_{3}$ and $\cdot \mathrm{OCH}_{3}$ free radicals under both conditions (Fig. 2 lines g-h). However, the signal intensity of $\cdot \mathrm{CH}_{3}$ was higher than that of $\cdot \mathrm{OCH}_{3}$ under anaerobic conditions (Fig. 2 line g), while the signal intensity of $\cdot \mathrm{OCH}_{3}$ was higher than that of $\cdot \mathrm{CH}_{3}$ under aerobic conditions (Fig. 2 line h). The difference in signals between samples prepared in different conditions suggested the oxidation of $\cdot \mathrm{CH}_{3}$ to $\cdot \mathrm{OCH}_{3}$ in the air, and inferred that oxygen could not be totally excluded under anaerobic conditions. When $0.2 \mathrm{~mL}$ of $100 \mathrm{mmol} / \mathrm{L}$ methyl gallate was added to the homogenized roots before addition of PBN and DMSO, the signals of PBN adducts were totally inhibited (Fig. 2 line i). Methyl gallate could scavenge . OH but could not scavenge $\cdot \mathrm{CH}_{3}$ (Takeshita et al., 2004). The signal inhibition demonstrated clearly that the ROS in maize roots stimulated by CTC was $\cdot \mathrm{OH}$.

The ROS level was correlated with the signal intensity of the second couple of the triplet. The signal intensity of $\mathrm{PBN} / \cdot \mathrm{OCH}_{3}$ and $\mathrm{PBN} / \cdot \mathrm{CH}_{3}$ was used to represent the $\cdot \mathrm{OH}$ intensity. A weak $\cdot \mathrm{OH}$ signal was found in the control (Fig. 2 line e), revealing the $\cdot \mathrm{OH}$ generation during normal cellular functions (Yin et al., 2007). The $\cdot \mathrm{OH}$ level increased with exposure to increasing CTC concentration (Figs. 2 and 3), and the maximum level (260\% of control) was observed for the CTC concentration of $50 \mathrm{mg} / \mathrm{L}$. The intensity of $\cdot \mathrm{OH}$ in maize roots correlated positively with the logarithm of CTC concentration exposed $(p<0.05)$. These results suggest the ability of CTC to stimulate the production of $\cdot \mathrm{OH}$ in the maize root. The $\cdot \mathrm{OH}$ is the most reactive species among the ROS. It immediately reacts with surrounding target molecules at the site where it is generated. The accumulation of $\cdot \mathrm{OH}$ in the maize root demonstrated that CTC could induce oxidative damage.

\subsection{Accumulation of CTC in maize roots}

The concentrations of CTC in maize roots increased with increasing CTC concentration in the growth medium (Fig. 3). Regression analysis demonstrated a positive rela- 


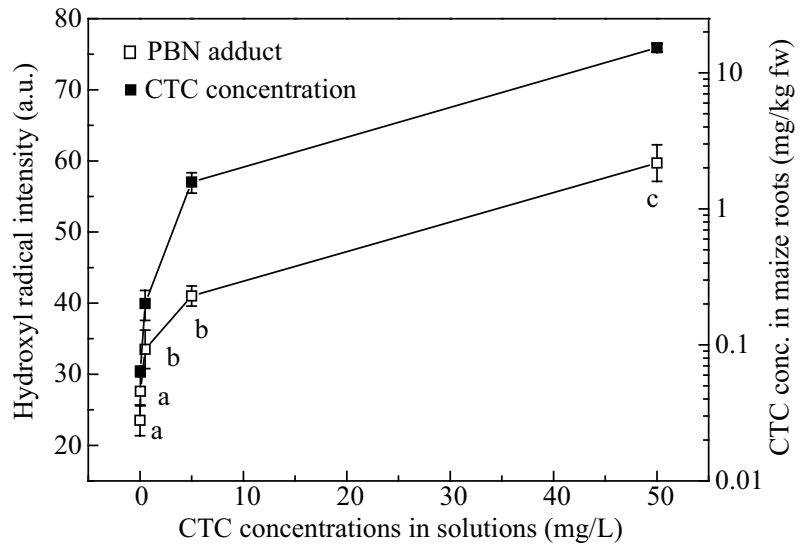

Fig. 3 EPR signal intensity of PBN adducts and concentrations of CTC in maize roots after exposure to different concentrations of CTC (different letters indicate significant differences at $p<0.05$. Values represent the mean and standard deviation of three replicates).

tion $(p<0.01)$ between the CTC contents $(y, \mathrm{mg} / \mathrm{kg}$ fresh weight) in roots of the treated groups and the exposure concentrations $(x, \mathrm{mg} / \mathrm{L})$. The regression equation is $y=$ $0.305 x+0.049, R^{2}=0.999$. These results suggest that the
-OH was induced by CTC accumulated in maize roots.

\subsection{Dynamic changes of MDA concentrations and an- tioxidative enzyme activities in maize seedling roots}

The levels of lipid peroxidation in maize roots were measured in terms of MDA content (Fig. 4a). The MDA contents increased with increasing CTC concentrations, that is, increased lipid peroxidation occurred with increasing CTC concentrations. After a 1-day exposure, significant accumulation of MDA contents were found when the CTC concentrations were higher than $0.5 \mathrm{mg} / \mathrm{L}$, while after a 5-day exposure, significant accumulation of MDA contents were found when the CTC concentration was higher than $0.05 \mathrm{mg} / \mathrm{L}$. For maize treated with $50 \mathrm{mg} / \mathrm{L}$ CTC, the MDA contents reached the highest intensity at day 3 and tended to decrease during the rest of the time. The MDA contents after 5-day exposure were linearly and positively correlated with the $\cdot \mathrm{OH}$ level $(p<0.05)$ in maize roots. Treatment with $200 \mu \mathrm{mol} / \mathrm{L} \mathrm{SB}$ decreased the level of MDA contents significantly (Fig. 4a).

Evidence of $\cdot \mathrm{OH}$ formation in vivo by EPR analysis

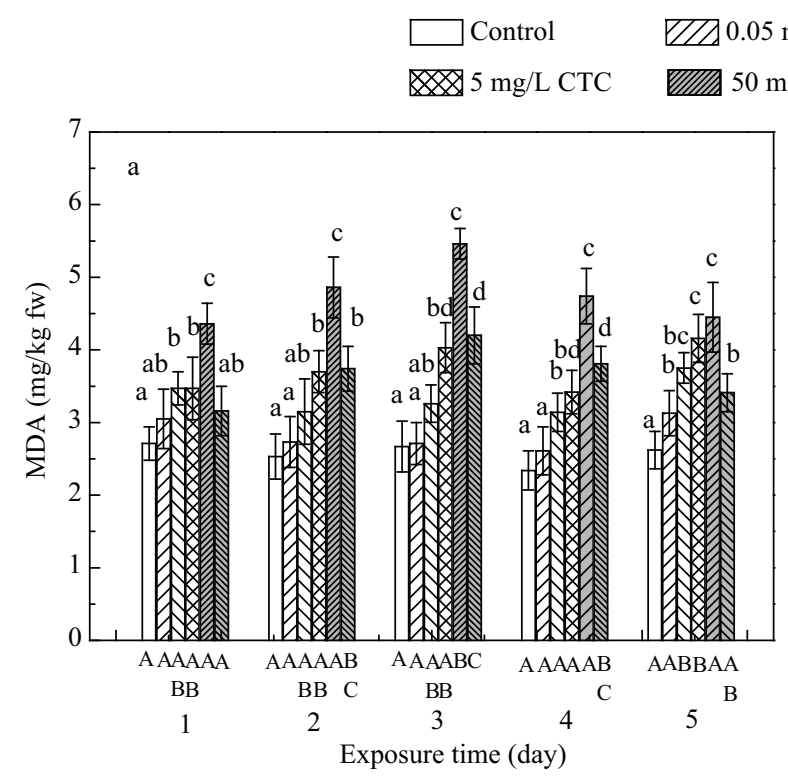

$\begin{array}{ll}\mathrm{L} \text { CTC } & 0.5 \mathrm{mg} / \mathrm{L} \mathrm{CTC} \\ \mathrm{CTC} & 50 \mathrm{mg} / \mathrm{L} \mathrm{CTC}+\mathrm{SB}\end{array}$
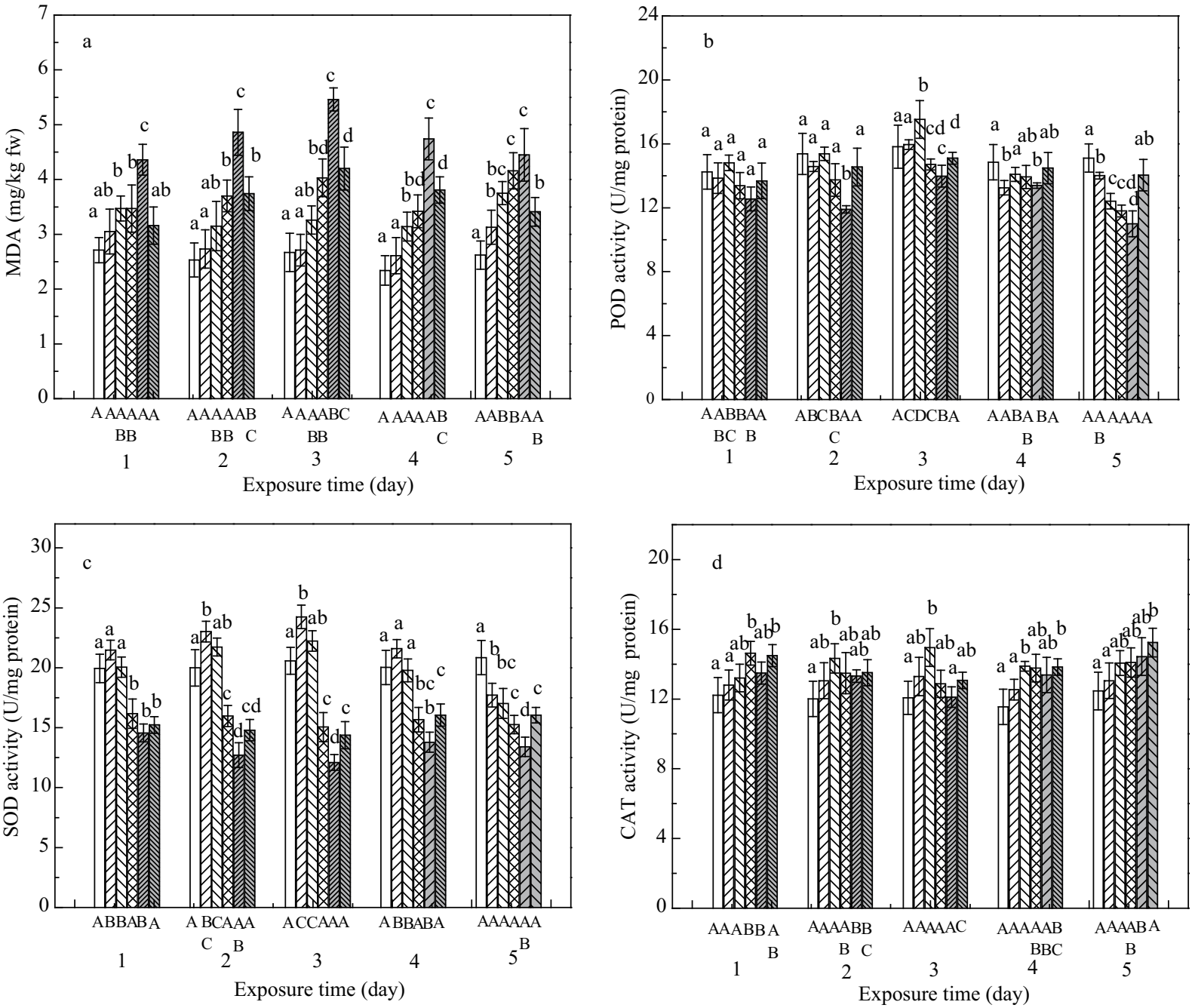

Fig. 4 Dynamic changes of MDA contents (a), and POD (b), SOD (c), and CAT (d) activities in maize seedlings (different capital letters indicate significant differences $(p<0.05)$ for the same treatments for different days; different lower case letters indicate significant difference $(p<0.05)$ for different treatments in the same days). 
indicated possible oxidative stress induced by CTC. The occurrence and accumulation of MDA in maize demonstrated the oxidative damage with the stress of CTC. MDA is the final product of lipid peroxidation and a sensitive diagnostic index of oxidative injury in cells. Detailed studies have provided evidence that many species exhibit an increased MDA content following oxidative stress produced by both organic (Yin et al., 2007) and inorganic pollutants (Lin et al., 2007). In this study, the positive correlation between MDA contents and $\cdot \mathrm{OH}$ levels, and the decreases of MDA contents in the presence of the $\cdot \mathrm{OH}$ scavenger SB indicated that $\cdot \mathrm{OH}$ may be involved in lipid peroxidation in CTC-treated maize roots.

Compared with the control, no significant change of POD activities was found for all treatments in the first two exposure days, except for a significant decrease of POD activity for the treatment of $50 \mathrm{mg} / \mathrm{L}$ after 2 days of exposure (Fig. 4b). After 3 days, POD activity for the treatment of $0.5 \mathrm{mg} / \mathrm{L} \mathrm{CTC}$ was higher $(p<0.05)$, while those for 5 and $50 \mathrm{mg} / \mathrm{L} \mathrm{CTC}$ treatments were lower $(p<0.05)$ than those of the control. After 5 days, POD activities decreased with increasing CTC concentration. A significant negative correlation was found between POD activities and the logarithm of CTC concentrations exposed ( $p<0.05$, Fig. $4 b)$. Increases $(p<0.05)$ of POD activities were found for samples from day 2, 3 and 5 of $50 \mathrm{mg} / \mathrm{L} \mathrm{CTC}$ and SB treated plants, compared with their corresponding samples of $50 \mathrm{mg} / \mathrm{L} \mathrm{CTC}$-treated plants.

The SOD activities in maize were lower $(p<0.05)$ than those of the control when CTC concentrations were higher than $5 \mathrm{mg} / \mathrm{L}$ over the whole exposure time (Fig. 4c). When the CTC concentration was $0.05 \mathrm{mg} / \mathrm{L}$, SOD activities increased in the first 2 and 3 days, then decreased. After 5 days, significant decreases of SOD activities were found for all CTC treatments. SOD activities positively correlated with the CTC concentrations in solution $(p<$ $0.05)$. The presence of SB increased the levels of SOD significantly $(p<0.05)$.

Among treatments with different CTC concentrations, significant increases $(p<0.05)$ of CAT activities were found for the samples from day 2,3 and 4 of $0.5 \mathrm{mg} / \mathrm{L}$ CTC-treated plants, compared with their corresponding control plants (Fig. 4d). The others displayed increased CAT activities, but not within the range of statistical significance. Samples treated with the mixture of $50 \mathrm{mg} / \mathrm{L}$ CTC and SB showed significant increases of CAT activities as compared with the control $(p<0.05)$, however, the increases were not significant when compared with those samples treated with $50 \mathrm{mg} / \mathrm{L} \mathrm{CTC}$ alone $(p>0.05)$.

Plants have antioxidant defense systems comprising POD, SOD and CAT which play important roles in scavenging ROS produced under oxidative stress (Alscher and Hess, 1993). The changes of these enzymes' activities may be considered as circumstantial evidence for enhanced production of ROS. The POD enzyme system is important in plant defense. Its general function is to fortify the cell wall, thus resisting disease progression (Hirata et al., 2000). SOD occurs in various cell compartments and catalyzes the disproportionation of superoxide anion $\left(\mathrm{O}_{2} \cdot{ }^{-}\right)$to $\mathrm{H}_{2} \mathrm{O}_{2}$ and $\mathrm{O}_{2}$ (Salin, 1988), while CAT and POD are important $\mathrm{H}_{2} \mathrm{O}_{2}$ scavengers, catalyzing the transformation of $\mathrm{H}_{2} \mathrm{O}_{2}$ to water. Both activation and inhibition of SOD, CAT and POD activities in plants exposed to oxidative stress have been reported in the literature (Guo et al., 2007; Lin et al., 2007). The levels of ROS and the extent of oxidative damage depend largely upon the whole antioxidant defense system and the co-operation or coordination among the ROS-scavenging enzymes. When $\cdot \mathrm{OH}$ is generated in excess or the cellular antioxidant defense is deficient, it can stimulate free-radical chain reactions and cause cellular damage. Farkas et al. (2007) reported that significant increases of POD activities occurred in the roots of tenday-old maize seedlings grown in $20 \mathrm{mg} / \mathrm{kg}$ CTC-treated soil. Results obtained from this experiment showed that significant increases of POD activities were only found in 5-day old maize seedling root samples from day 3 of the $0.5 \mathrm{mg} / \mathrm{L} \mathrm{CTC}$ treated plants, while insignificant changes or significant decreases relative to their corresponding control plants were found for other treatments. These phenomena suggested that the antioxidative enzyme activities were chemical concentration and exposure time dependent. Moreover, the sensitivity and toxicity of pollutants to plants are influenced by the life-stage or biological process. By comparison, the early seedlings are more sensitive to pollutants because some of the defense mechanisms have not been developed. The decreased activities of POD and SOD, and unchanged activities of CAT after 5 days of exposure suggested that these antioxidative enzymes could not scavenge ROS efficiently.

\section{Conclusions}

In this article, we have demonstrated that CTC can be taken up by maize and induce $\cdot \mathrm{OH}$ production, and provided strong evidence that $\cdot \mathrm{OH}$ production leads to oxidative damage in maize roots. To our knowledge, this is the first study to demonstrate that CTC could stimulate $\cdot \mathrm{OH}$ production in plants. However, the mechanisms of CTC toxicity, including oxidative stress, are far from understood, and further research is needed in order to provide solid information regarding the mechanism of CTC toxicity to plants.

\section{Acknowledgments}

This work was supported by the National Natural Science Foundation of China (No. 20877087, 40730740) and the Major Science and Technology Program for Water Pollution Control and Treatment (No. 2009ZX07207-002).

\section{References}

Aebi H, 1984. Catalase in vitro. Methods in Enzymology, 105: 121-126.

Alscher R G, Hess J L, 1993. Antioxidants in Higher Plants. CRC Press, Boca Raton, Florida, USA.

Beauchamp C, Fridovich I, 1971. Superoxide dismutase: improved assays and an assay applicable to acrylamide gels. Analytical Biochemistry, 44(1): 276-287. 
Boxall A B A, Johnson P, Smith E J, Sinclair C J, Stutt E, Levy L S, 2006. Uptake of veterinary medicines from soils into plants. Journal of Agricultural and Food Chemistry, 54(6): 2288-2297.

Bradford M M, 1976. A rapid and sensitive method for the quantitation of microgram quantities of protein utilizing the principle of protein-dye binding. Analytical Biochemistry, 72(1-2): 248-254.

Farkas M H, Berry J O, Aga D S, 2007. Chlortetracycline detoxification in maize via induction of glutathione $s$-transferases after antibiotic exposure. Environmental Sciences and Technology, 41(4): 1450-1456.

Guo B, Liang Y C, Zhu Y G, Zhao F J, 2007. Role of salicylic acid in alleviating oxidative damage in rice roots (Oryza sativa) subjected to cadmium stress. Environmental Pollution, 147(3): 743-749.

Heath R L, Packer L, 1968. Photoperoxidation in isolated chloroplasts: I. Kinetics and stoichiometry of fatty acid peroxidation. Archives of Biochemistry and Biophysics, 125(1): 189-198.

Hirata T, Ashida Y, Mori H, Yoshinaga D, Goad L J, 2000. A 37-kDa peroxidase secreted from liverworts in response to chemical stress. Phytochemistry, 55(3): 197-202.

$\mathrm{Hu} J$ Y, Shi J C, Chang H, Li D, Yang M, Kamagata Y C, 2008. Phenotyping and genotyping of antibiotic-resistant Escherichia coli isolated from a natural river basin. Environmental Sciences and Technology, 42(9): 3415- 3420 .

Jøgensen S E, Halling-Sønsen B, 2000. Drugs in the environment. Chemosphere, 40(7): 691-699.

Kim S C, Carlson K, 2007. Temporal and spatial trends in the occurrence of human and veterinary antibiotics in aqueous and river sediment matrices. Environmental Sciences and Technology, 41(1): 50-57.

Kong W D, Zhu Y G, Liang Y C, Zhang J, Smith F A, Yang M, 2007. Uptake of oxytetracycline and its phytotoxicity to alfalfa (Medicago sativa L.). Environmental Pollution, 147(1): 187-193.

Kumar K, Gupta S C, Baidoo S K, Chander Y, Rosen C J, 2005. Antibiotic uptake by plants from soil fertilized with animal manure. Journal of Environmental Quality, 34(6): 2082 2085.

Lagrimini L M, 1991. Wound-induced deposition of polyphenols in transgenic plants overexpressing peroxidase. Plant Physiology, 96(2): 577-583.

Lin R Z, Wang X R, Luo Y, Du W C, Guo H Y, Yin D Q, 2007. Effects of soil cadmium on growth, oxidative stress and antioxidant system in wheat seedlings (Triticum aestivum L.). Chemosphere, 69(1): 89-98.

Liu F, Ying G G, Tao R, Zhao J L, Yang J F, Zhao L F, 2009. Effects of six selected antibiotics on plant growth and soil microbial and enzymatic activities. Environmental Pollution, 157(5): 1636-1642.

Liu X L, Zhang S Z, Shan X Q, Christie P, 2007. Combined toxicity of cadmium and arsenate to wheat seedlings and plant uptake and antioxidative enzyme responses to cadmium and arsenate co-contamination. Ecotoxicology and Environmental Safety, 68(2): 305-313.

Matyar F, Kaya A, Dinçr S, 2008. Antibacterial agents and heavy metal resistance in Gram-negative bacteria isolated from seawater, shrimp and sediment in Iskenderun Bay, Turkey. Science of the Total Environment, 407(1): 279-285.

Migliore L, Cozzolino S, Fiori M, 2003. Phytotoxicity to and uptake of enrofloxacin in crop plants. Chemosphere, 52(7): 1233-1244.

Mompelat S, Le Bot B, Thomas O, 2009. Occurrence and fate of pharmaceutical products and by-products, from resource to drinking water. Environment International, 35(5): 803-814.

Polle A, Eiblmeier M, Sheppard L, Murray M, 1997. Responses of antioxidative enzymes to elevated $\mathrm{CO}_{2}$ in leaves of beech (Fagus sylvatica L.) seedlings grown under a range of nutrient regimes. Plant, Cell and Environment, 20(10): 1317-1321.

Salin M L, 1988. Toxic oxygen species and protective systems of the chloroplast. Physiologia Plantarum, 72(3): 681-689.

Sarmah A K, Meyer M T, Boxall A B A, 2006. A global perspective on the use, sales, exposure pathways, occurrence, fate and effects of veterinary antibiotics (VAs) in the environment. Chemosphere, 65(5): 725-759.

Schneider M J, Braden S E, Reyes-Herrera I, Donoghue D J, 2007. Simultaneous determination of fluoroquinolones and tetracyclines in chicken muscle using HPLC with fluorescence detection. Journal of Chromatography B, 846(1-2): $8-13$.

Shi H H, Wang X R, Luo Y, Su Y, 2005. Electron paramagnetic resonance evidence of hydroxyl radical generation and oxidative damage induced by tetrabromobisphenol $\mathrm{A}$ in Carassius auratus. Aquatic Toxicology, 74(4): 365-371.

Spisso B F, de Oliveira e Jesus A L, de Araúo M A Jr, Monteiro M A, 2007. Validation of a high-performance liquid chromatographic method with fluorescence detection for the simultaneous determination of tetracyclines residues in bovine milk. Analytica Chimica Acta, 581(1): 108-117.

Takeshita K, Fujii K, Anzai K, Ozawa T, 2004. In vivo monitoring of hydroxyl radical generation caused by X-ray irradiation of rats using the spin trapping/EPR technique. Free Radical Biology and Medicine, 36(9): 1134-1143.

Yin Y, Jia H X, Sun Y Y, Yu H X, Wang X R, Wu J C et al., 2007. Bioaccumulation and ROS generation in liver of Carassius auratus, exposed to phenanthrene. Comparative Biochemistry and Physiology Part C: Toxicology $\mathcal{F}$ Pharmacology, 145(2): 288-293. 